\title{
PULMONARY ARTERY ANEURYSM IN A YOUNG CHILD
}

\author{
BY \\ D. M. G. BEASLEY, J. T. CHESTERMAN and C. C. HARVEY \\ From the City General Hospital, Sheffield
}

(RECEIVED FOR PUBLICATION MARCH 11, 1954)

Fortune seldom provides that the onset of a rare and grave disease process can be recorded visually, as in this case of pulmonary artery aneurysm in an infant between the ages of 13 and 15 months. The study was carried to surgical exploration at 17 months of age, with the child in respiratory and circulatory collapse. Our histological interpretation is based on the operation specimen of the left lung, as permission for necropsy was refused. It is thus impracticable to discuss certain findings which during life caused the gravest diagnostic anxiety, and may have prejudiced approach to the lesion, namely, splenomegaly, severe hypochromic anaemia and contralateral pleurisy.

There have been two comprehensive reviews of the literature. First, Boyd and McGavack (1939) noted 111 cases proven at necropsy; secondly, Deterling and Clagett (1947) added another 36 cases proven at necropsy, bringing the total of proven cases to 147. A recent search through the literature reveals another handful recorded since then. Many pulmonary aneurysms doubtless occur unrecorded.

About one-third of pulmonary aneurysms occur under the age of 30 , and nearly half under the age of 40, with equal sex distribution. From Boyd and McGavack's cases, $70 \%$ involved the trunk of the artery only, in some $15 \%$ the trunk plus one or both main branches, in $15 \%$ one or other main branch only. A striking feature is the frequency with which congenital cardiovascular anomalies are found: Deterling and Clagett inculpate such anomalies in $50 \%$ of cases, persistent ductus arteriosus and septal defects the most commonly. Lindert and Correll (1950) collect 29 cases (and add another of their own) of persistent ductus arteriosus with pulmonary artery aneurysm. The clinical picture may be that caused by any tumour in the chest, or may be overshadowed by the associated cardiovascular anomaly if present. A sensation of suffocation or "fullness" is described, commonly attributed by the patient to mechanical pressure. Blood-stained sputum or frank haemoptysis may occur. Cough is present in $80 \%$ of patients. Oedema is late and usually slight.
There may be localized swelling or prominence of the chest wall with a palpable thrill. Israels (1951) considers the presence of a rough loud systolic murmur in the second or third interspace the outstanding feature on physical examination. Enlargement of the right heart is nearly always present.

The radiological findings are the most helpful in diagnosis. Deterling and Clagett describe the finding on screening of a more or less well defined pulsatile hilar mass distinct from the aortic shadow. There may also be evidence of right and left enlargement of the heart and evidence also of any associated cardiovascular anomaly.

Death is usually due to heart failure, to bacterial endocarditis or endarteritis, or to rupture of the aneurysm.

The youngest recorded case is that described by Zuber (1904) of a 5-month-old child who from birth failed to thrive, and, dying from bronchopneumonia, was found at necropsy to have a fusiform aneurysm of the pulmonary artery, involving the trunk and both main branches. The smaller branches also showed many saccular dilatations.

\section{Case Report}

This child, aged nearly 13 months, was first admitted under our care with an upper respiratory infection on April 14, 1952, with three weeks' history of fever, coughing and discharge from the ear. There had been two convulsions on a day two weeks before admission.

She was the second child of healthy parents and had weighed $6 \frac{1}{2} \mathrm{lb}$. when born into a very poor, overcrowded home. At the age of 7 months she had been in hospital with otitis media.

She was still unweaned from the bottle, and had not received regular vitamin supplements.

Her weight on admission was $20 \mathrm{lb} .6 \mathrm{oz}$. $(9 \cdot 3 \mathrm{~kg}$.). There were no abnormal pulmonary signs on admission, but bronchial spasm was observed during her stay in hospital. The spleen was enlarged and firm $3 \mathrm{~cm}$. below the left rib margin. Her conspicuous pallor was found to be due to a hypochromic anaemia, the blood count on admission being haemoglobin $6 \cdot 8 \mathrm{~g}$. \%, red cells $4,400,000$ per c.mm., white cells 16,000 per c.mm. (neutrophils $60 \%$, lymphocytes $31 \%$, monocytes $9 \%$ ), 
platelets 124,000 per c.mm., bleeding time (Duke) $6 \frac{1}{4} \mathrm{~min}$., coagulation time (capillary) $3 \frac{1}{2} \mathrm{~min}$.

The blood Wassermann and Kahn tests were negative.

The chest radiograph on the day of admission showed normal heart, mediastinum and diaphragm outlines and normal lung markings, without sign of collapse, effusion or consolidation (Fig. 1). The tuberculin jelly test was

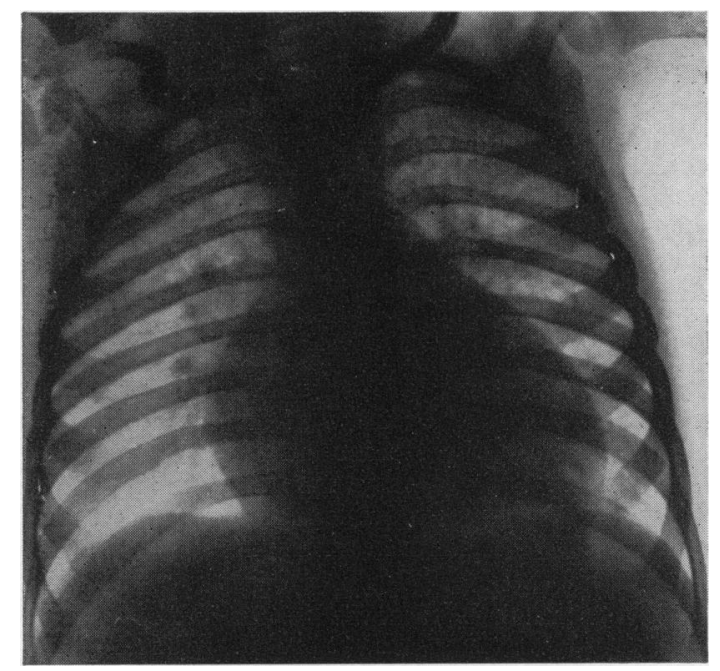

FIG. 1.

Radiograph taken on April 15.

negative. A catheter specimen of urine showed no urinary infection.

Treatment was by oral sulphadimidine, intramuscular penicillin and oral ferrous sulphate. The haemoglobin rose to $11 \cdot 8 \mathrm{~g}$. \% (with $4,200,000$ red cells) in four weeks, and her weight rose to $21 \mathrm{lb} .7 \mathrm{oz}$. five weeks after admission, when she was discharged to her home. The splenomegaly persisted.

She developed measles on the day after discharge. Three weeks later, on June 9, 1952, she was readmitted, gravely ill, on a plea of 'haemoptysis'. In this brief interval she had lost $5 \frac{3}{4} \mathrm{lb}$. $(2 \cdot 6 \mathrm{~kg}$.), now weighing $15 \mathrm{lb} .11 \mathrm{oz}$. $(6 \cdot 7 \mathrm{~kg}$.). She was bleeding from a crusted left nostril, which was considered the probable source of her blood-spitting. Breathing was rapid, with coarse rhonchi and general bronchial spasm. A further course of sulphadimidine, penicillin and ferrous sulphate was begun on readmission. A radiograph on June 10 showed on the right side a raised diaphragm with an opacity above it laterally, suggesting a small effusion. From the right lung root a diffuse central hazy area extended upwards. The left diaphragm was clear, and the middle zone of the left lung field was occupied by a large opaque area which was regarded as inflammatory in nature, or possibly an interlobar effusion. This film, taken eight weeks after the original clear chest film, showed the final lesion almost fully developed.

These appearances, with the alarming rapid deteriora- tion in three weeks, led to urgent rechecking of the tuberculin reaction, which proved negative to jelly and Mantoux tests to 1 in 100 . Gastric washings were thrice negative for Myco. tuberculosis. The cerebrospinal fluid on June 18 showed normal levels of protein (25 mg. \%), chloride (730 mg. \%) and sugar (54 mg. \%), with no cells or organisms.

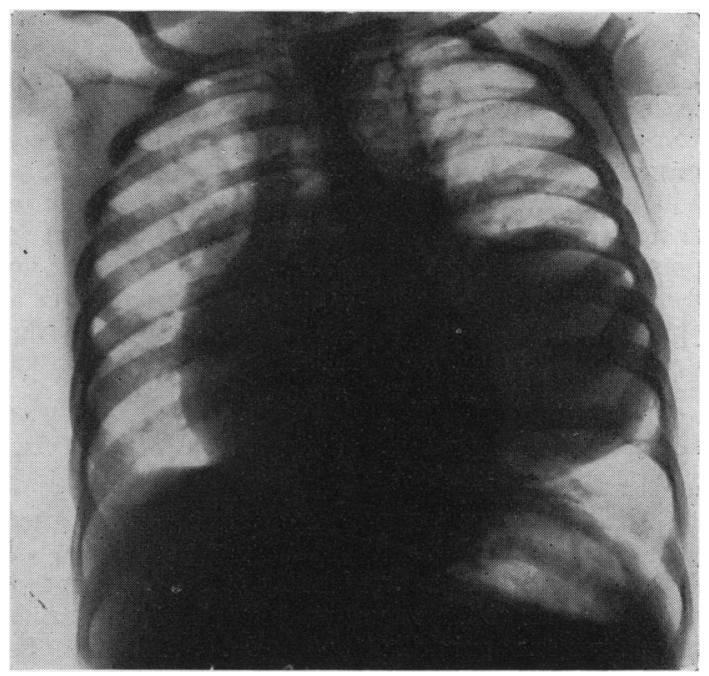

FIG. 2.

Radiograph taken on July 18.

The persistent splenomegaly prompted a red cell fragility estimation, in which haemolysis occurred normally between saline dilutions of $0.48 \%$ and $0.28 \%$. The blood count on June 21 gave haemoglobin $8.9 \%$, red cells 4,400,000, white cells 9,000 (neutrophils $25 \%$, eosinophils $2 \%$, lymphocytes $69 \%$, monocytes $4 \%$ ). By August 1 the haemoglobin had risen to $13 \cdot 3 \mathrm{~g}$. \%, with 5,200,000 red cells and 14,200 white cells (neutrophils $64 \%$, lymphocytes $32 \%$, monocytes $4 \%$ ).

From July 12 to 20 the respiratory rate was exceptionally rapid and embarrassed, up to 60 and 65 per minute, with a subsequent fall to 45 per minute. The child remained afebrile throughout her second stay in hospital.

The radiographic appearances in the left lung sharpened to reveal a clear-cut, globular opacity postero-lateral to the heart, clear of the base, and extending out to the ribs (Fig. 2). This showed no pulsation on screening on July 29. The right basal opacity became less dense, suggestive of residual thickened pleura. An intravenous pyelogram on July 24 suggested normal calyces in both kidney areas.

On August 1, 1952, she was transferred to the Children's Hospital, Sheffield, under the care of Professor R. S. Illingworth, on the suspicion of a malignant neoplasm or possibly encysted interlobar empyema. Aspiration by syringe yielded blood. No exploring needle had ever previously been passed into the chest. 
She was transferred on August 13 to the City General Hospital for exploratory thoracotomy.

The consensus of opinion suggested the diagnosis of a tumour of the lower lobe of the left lung.

Operation was performed on August 14, 1952. The anaesthetic was induced with gas, oxygen and ether maintained after intratracheal intubation with cyclopropane and oxygen. The chest was opened by a left postero-lateral thoracotomy with resection of the sixth rib. A large rounded mass was found in the lower lobe with some recent haemorrhage at the site of previous aspiration. The mass appeared to be of soft, solid consistency, and on freeing it the mass ruptured and bled profusely. The haemorrhage was controlled by sutures and further exploration showed the mass to be a saccular aneurysm of the left pulmonary artery. Owing to the poor condition of the patient, removal of the lung was decided upon as the quickest method of removing an almost certainly fatal lesion. Unfortunately, cardiac irregularity became very marked after pneumonectomy and the child died half an hour later.

Pathological Report. The left lung was received fixed and rather contracted.

NAKED-EYE DESCRIPTION. The left pulmonary artery is enlarged at its origin and from its posterior lateral wall through an orifice approximately $2 \times 1.75 \mathrm{~cm}$. in diameter leads to an aneurysm which, in its contracted state, measures approximately $4 \times 5.5 \times 3.5 \mathrm{~cm}$. The aneurysm obtrudes on the interlobar fissure. It has a well-marked, pale wall varying considerably in thickness $(0.1$ to $0.3 \mathrm{~cm}$. $)$ and regularity. Attached to the inner wall of the aneurysm are many small and large thrombi of apparently diverse ages.

Histology. Elastic fibres are present within the main pulmonary artery but disappear at the beginning of the aneurysmal dilatation. The wall of the aneurysm consists almost entirely of dense connective tissue. Blood vessels beyond the wall of the artery show extensive endarteritis. No foci of inflammation are seen in the aneurysm wall suggesting a rheumatic process or syphilis. The lung elsewhere shows evidence of recent and old bleeding but no evidence of chronic infection or tuberculous disease.

The specimen is an aneurysm arising from the lateral aspects of the left pulmonary artery. The aetiology is not apparent from the histological findings. The absence of any local sepsis and the unusual site, together with the long history, may indicate that the primary condition was a developmental defect in the vessel wall. An analogy with cerebral aneurysm is perhaps the most apt.

Whether the wall of the artery gave way at the site of a congenital defect or 'berry' aneurysm, or whether mycotic softening occurred through infection within the vessel, or whether an adjacent lung abscess caused and received the eruption of blood, it is not possible to determine, as enlargement of the sac will have obliterated any evidences of origin. This limited tissue study is compatible with the view that during a severe acute wasting respiratory infection (probably a complication of measles) a 'blow-out' occurred at the fork of the left pulmonary artery into the substance of the lower lobe of the left lung: a very large false aneurysmal sac was rapidly formed by compression of surrounding lung tissue and clotting within the aneurysm.

It is a pleasure to acknowledge our indebtedness to Professor R. S. Illingworth, to Dr. J. Wilkie and Dr. T. Lodge for radiological studies, to Dr. E. Travers in the earlier pathological studies, to Dr. J. L. Emery for the histological report and advice, and to Dr. W. Doran, the family doctor.

\section{REFERENCES}

Boyd, L. J. and McGavack, T. H. (1939). Amer. Heart J., 18, 562. Deterling, R. A. and Clagett, O. T. (1947). Ibid., 34, 471 .

Israels, M. G. (1951). Canad. med. J., 64. 433.

Lindert, M. C. F. and Correll, H. L. (1950). J. Amer. med. Ass., $143,888$.

Zuber, B. (1904). Jb. Kinderheilk., 59, 30. 